\title{
Direct and indirect vector control of a doubly fed induction generator based in a wind energy conversion system
}

\author{
Manale Bouderbala ${ }^{1}$, Badre Bossoufi $^{2}$, Ahmed Lagrioui $^{3}$, Mohammed Taoussi $^{4}$, Hala Alami Aroussi $^{5}$, \\ Yasmine Ihedrane ${ }^{6}$ \\ 1,2,5 Laboratory of Electrical Engineering and Maintenance, Higher School of Technology, Oujda, Morocco \\ ${ }^{3}$ Department of Electrical and Computer Engineering The Higher National School of Arts and Trades, Moulay Ismail \\ University Meknes, Morocco \\ ${ }^{2,4,6}$ LISTA Laboratory, Faculty of Sciences Dhar El Mahraz, University Sidi Mohammed Ben Abdellah Fez - Morocco
}

\begin{tabular}{l}
\hline \hline Article Info \\
\hline Article history: \\
Received Jun 4, 2018 \\
Revised Nov 16, 2018 \\
Accepted Des 15, 2018 \\
\hline Keywords: \\
Wind power \\
Doubly- fed induction \\
generator (DFIG) \\
Direct field oriented control \\
(DFOC) \\
Indirect field oriented control \\
(IFOC) \\
MPPT control
\end{tabular}

\begin{abstract}
In the recent years, the development and the exploitation of renewable energy knew a great evolution. Among these energy resources, the wind power represents an important potential for that the wind system has been the subject of several researches. The purpose of this study is to improve the power extracted from wind energy, taking into consideration the variation of wind speed which causes a problem in energy production. For this purpose, we have controlled the powers whether it is active or reactive delivered by the generator. This paper, presents essentially the modeling and control of doubly- fed induction generator (DFIG), which is connected to a variable speed wind turbine. Firstly, the model of the wind power system with the maximum power point tracking (MPPT) strategy is shown. Then, the modeling of doubly- fed induction generator (DFIG) and its power control is presented. Finnaly, to ensure the attitude of these controls the simulations is presented in the Matlab/Simulink environment.
\end{abstract}

Copyright (c) 2019 Insitute of Advanced Engineeering and Science. All rights reserved

Corresponding Author:

Bouderbala Manale,

Electrical Engeneering and Maintenance Laboratory,

Mohammed First University, Higher School of Technologie Oujda, Morocco.

Email: Bouderbala_manale1718@ump.ac.ma

\section{INTRODUCTION}

Following the strong industrialisation, electric energy will always reside an energy that humanity can not do without it. Fossil fuels have long been used in the production of electrical energy, these fossil fuels are causing harmful damage to the environment. [1] To meet the high demand of energy and at the same time keep the environment safe, the majority of countries has opted for the use of renewable energies. These energies are inexhaustible, clean and do not create greenhouse gases unlike fossil fuels. [2][3]

Among the renewable energies, wind energy is experiencing a significant growth and is considered as a mature and economical technology[4]. However, the problem is that this resource is characterized by variable wind speed [5]. For this reason, we have opted for the generator doubly fed induction, as well as other advantages such as; reducing the sizing of the converters, and improving the quality of the energy produced. On the other hand, the control of this machine remains the most important and complex phase.[6][7]

In that way we will start our study by modeling the wind turbine. Then, the MPPT control which ensures an important role to extract the maximum of power. Thereafter, the modeling of the DFIG, and also the power control which is done by the vector control. In terms of this later we have two types: direct field oriented control(DFOC) and indirect oriented field control(IFOC). Finally, the results of the simulations will be presented in the environment Matlab/Simulink in order to conclude the most efficient and robust control also the impact of the MPPT control on the system . 


\section{MODELLING OF WIND TURBIN}

The wind turbine allows the transformation of kinetic energy into mechanical energy and then into electrical energy through a generator. Wind power depends on the surface to be swept (S), wind speed (v) and air density $(\rho)$. Based on the fluid mechanics equations we have the following equation [8][9]:

$$
P v=\frac{\rho . S . V^{3}}{2}
$$

According to Betz's law, a wind turbine can never convert more than 16/27 (or \%59) of the kinetic energy of the wind. Cp expresses the aerodynamic efficiency of the wind turbine. It depends on the ratio $(\lambda)$, and the angle of orientation of the blades $(\beta)$. The ratio $(\lambda)$ and $\mathrm{Cp}$ are expressed by the following relations [3]:

$$
\begin{gathered}
\lambda=\frac{R \cdot \Omega_{t}}{V} \\
C_{p}(\lambda, \beta)=(0.5-0.0167 \cdot(\beta-2)) \cdot \sin \left(\frac{\pi \cdot(\lambda+0.1)}{18.5-0.3 \cdot(\beta-2)}\right)-0.00184 \cdot(\lambda-3) \cdot(\beta-2)
\end{gathered}
$$

Where $\Omega_{t}$ is the speed of the turbine, $\mathrm{R}$ is the wind turbine radius.

The aerodynamic power, which is converted by a wind turbine depends on the power coefficient $\mathrm{Cp}$, the following equation shows it [2][4]:

$$
P_{a e r}=C_{p}(\lambda, \beta) \cdot P_{v}
$$

The following relationship describes the aerodynamic torque

$$
T_{a e r}=\frac{P_{a e r}}{\Omega_{t}}=C_{p}(\lambda, \beta) \cdot \frac{\rho \cdot S \cdot V^{3}}{2 . \Omega_{t}}
$$

In order to adapt the slow speed of the turbine to the speed of the generator, a multiplier is added, this latter is modelled by the following equations [6]:

$$
\begin{gathered}
C_{g}=\frac{C_{t}}{G} \\
\Omega_{t}=\frac{\Omega_{m e c}}{G}
\end{gathered}
$$

Where $\mathrm{Cg}$ is the generator torque, $\Omega_{m e c}$ is the high speed of the generator, G: multiplier gain

From the fundamental equation of the dynamics we can determine the mechanical speed, however the mechanical torque is giving by [5][4]:

$$
J \frac{d \Omega_{m e c}}{d t}=T_{m e c}=T_{g}-T_{e m}-f . \Omega_{m e c}
$$

Where $T_{e m}$ is the electromagnetic torque, $T_{m e c}$ is themechanical torque, $\mathrm{f}$ is the viscous friction torque, $\mathrm{J}$ is the total inertia.

\section{MAXIMUM POWER POINT TRACKING CONTROL}

The goal of the MPPT is to optimize the wind energy captured by following the optimal speed. In order to recover as much energy as possible from the wind turbine, we must continuously adapt the mechanical speed of the DFIG to the wind speed. Therefore, it is possible to estimate in real time the value of the wind speed. Then, the electromagnetic torque extracted from the MPPT control is applied to the DFIG to sure that the generator operates at its optimal speed. This diagram as shown in Figure 1 illustrates the wind turbine model with the MPPT control model [3][9]: 


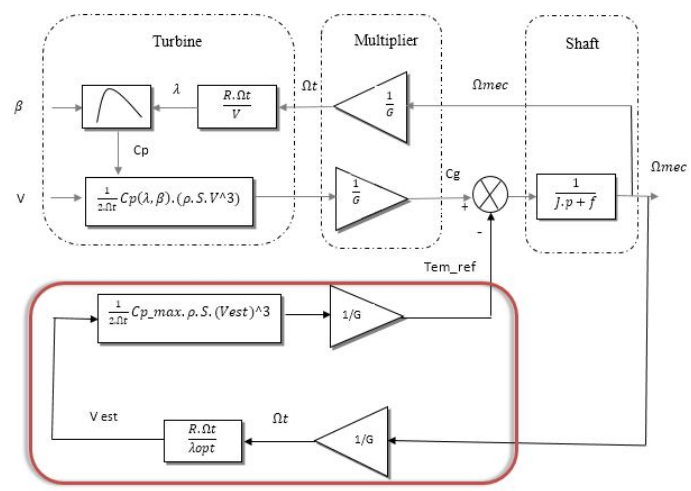

Figure 1. Turbine and MPPT model

The estimated value of the wind speed is given by:

$$
V_{e s t}=\frac{R . \Omega_{t}}{\lambda_{o p t}}
$$

The expression of the reference power becomes:

$$
P_{\text {aer_ref }}=C_{p_{\max }}(\lambda, \beta) \cdot \frac{\rho \cdot S \cdot V_{e s t}{ }^{3}}{2}
$$

The expression of the reference electromagnetic torque becomes:

$$
T_{\text {em_ref }}=\frac{P_{\text {aer_ref }}}{\Omega_{t}}=\frac{1}{2} \cdot C_{p_{\max }}(\lambda, \beta) \cdot \frac{\rho \cdot \Pi \cdot R^{5}}{\lambda_{C p \max ^{3}}} \cdot \Omega_{t}{ }^{2}
$$

\section{MODELLING OF THE DFIG}

The stator of the machine is directly connected to the power grid, but the rotor is connected through the power electronics. The mathematical model of DFIG in the park referential $(d-q)$ is given by the following equations [10][11][12][13]:

$V_{s d}, V_{s q}, \Phi_{s d}, \Phi_{s q}$ are respectively the equations of the voltages and stator flux in the d-q reference.

$$
\begin{aligned}
& V_{s d}=R_{s} \cdot I_{s d}+\frac{d \Phi_{s d}}{d t}-\Phi_{s q} \cdot \omega_{s} \\
& V_{s q}=R_{s} \cdot I_{s q}+\frac{d \Phi_{s q}}{d t}-\Phi_{s d} \cdot \omega_{s} \\
& \Phi_{s d}=L_{s} \cdot I_{s d}+M \cdot I_{r d} \\
& \Phi_{s q}=L_{s} \cdot I_{s q}+M \cdot I_{r q}
\end{aligned}
$$

$V_{r d}, V_{r q}, \Phi_{r d}, \Phi_{r q}$ are respectively the equations of the voltages and rotor flux in the d-q reference.

$$
\begin{aligned}
& V_{r d}=R_{r} \cdot I_{r d}+\frac{d \Phi_{r d}}{d t}-\Phi_{r q} \cdot \omega_{r} \\
& V_{r q}=R_{r} \cdot I_{r q}+\frac{d \Phi_{r q}}{d t}-\Phi_{r d} \cdot \omega_{r} \\
& \Phi_{r d}=L_{r} \cdot I_{r d}+M \cdot I_{s d} \\
& \Phi_{r q}=L_{r} \cdot I_{r q}+M \cdot I_{s q}
\end{aligned}
$$

$\mathrm{Rs}, \mathrm{Rr}$ : stator and rotor resistances.

Ls,Lr: cyclic stator and rotor Inductances.

M: mutual inductance.

The frequency of the stator voltage is being imposed by the grid, in the opposite the pulsation of the rotor currents is given by:

$$
\omega_{r}=\omega_{s}-\omega \quad \text { with } \quad \omega=p . \Omega
$$

p: Number of pole pairs of the machine.

$\omega_{s}, \omega_{r}$ : Pulse of the stator and rotor electrical quantities respectively .

The Electromagnetic torque is expressed by: 


$$
T_{e m}=p \cdot \frac{M}{L_{s}} \cdot\left(\phi_{s q} \cdot I_{r d}-\phi_{s d} \cdot I_{r q}\right)
$$

The Active and reactive stator powers are:

$$
\begin{aligned}
& P_{s}=V_{s d} \cdot I_{s d}+V_{s q} \cdot I_{s q} \\
& Q_{s}=V_{s q} \cdot I_{s d}+V_{s d} I_{s q}
\end{aligned}
$$

\section{FIELD ORIENTED CONTROL}

Vector control is one of the most widely used techniques for controlling electrical machines. It is based on the fact that the machine is similar to a DC machine with separate excitation, this latter ensures a natural decoupling between currents and flux. [14][15]

According to the equation (15) we see clearly the strong coupling between the fluxes and the currents rotoric and statoric which generates a difficulty in the control of the DFigure The principle of vector control is to orient the flux of the machine in one of the two axes d or q. In our case and in order to simplify the control of stator power (active or reactive), we use an orientation on the d axis. [2][12]

However:

$$
\Phi_{s d}=\Phi_{s} \quad \text { and } \quad \Phi_{s q}=0
$$

The expressions of the electromagnetic torque becomes:

$$
T_{e m}=-\frac{3}{2} \cdot p \cdot \frac{M}{L_{s}} \cdot \phi_{s d} \cdot I_{r q}
$$

The expressions of the stator voltages becomes:

$$
\begin{aligned}
& V_{s d}=R_{s} \cdot I_{s d}+\frac{d \Phi_{s d}}{d t} \\
& V_{s q}=R_{s} \cdot I_{s q}+\Phi_{s d} \cdot \omega_{s}
\end{aligned}
$$

For medium and high power machines, stator resistances are neglected [9], therefore the stator voltage equations become:

$$
\begin{aligned}
& V_{s d}=\frac{d \Phi_{s d}}{d t} \\
& V_{s q}=\Phi_{s d} \cdot \omega_{s}
\end{aligned}
$$

In steady state, it is assumed that the flow is constant, thus:

$$
\begin{gathered}
V_{s d}=0 \\
V s q=V_{s}=\Phi_{s} \cdot \omega_{s} \\
\Phi_{s d}=\Phi_{s}=L_{s} \cdot I_{s d}+M \cdot I_{r d} \\
\Phi_{s q}=0=L_{s} \cdot I_{s q}+M \cdot I_{r q}
\end{gathered}
$$

From the equation (22), we deduce the equations linking between stator and rotor currents:

$$
\begin{aligned}
& I_{s d}=\frac{\Phi_{s}}{L_{s}}-\frac{M}{L_{s}} \cdot I_{r d} \\
& I_{s q}=-\frac{M}{L_{s}} \cdot I_{r q}
\end{aligned}
$$

The relations of the powers become :

$$
\begin{aligned}
& P_{s}=V_{s q} \cdot I_{s q} \\
& Q_{s}=V_{s q} \cdot I_{s d}
\end{aligned}
$$

To express the power relations as a function of the rotor currents, we replace in the previous equation the currents by the equation (23):

$$
\begin{aligned}
& P_{s}=-\frac{V_{s} \cdot M}{L_{s}} \cdot I_{r q} \\
& Q_{s}=\frac{V_{s}^{2}}{L_{s} \cdot \omega_{s}}-\frac{V_{s} \cdot M}{L_{s}} \cdot I_{r d}
\end{aligned}
$$


By replacing flux and stator currents in the equation (13) by the expression (23) we obtain:

$$
\begin{aligned}
& \Phi_{r d}=\left(L_{r}-\frac{M^{2}}{L_{s}}\right) \cdot I_{r d}+\frac{V s \cdot M}{L_{s} \cdot \omega_{s}} \\
& \Phi_{r q}=\left(L_{r}-\frac{M}{L_{s}}\right) \cdot I_{r q}
\end{aligned}
$$

In order to control the generator ,these expressions are established showing the relationship between the currents and the rotor voltages that will be applied to it.

$$
\begin{aligned}
& V_{r d}=R_{r} \cdot I_{r d}+\left(L_{r}-\frac{M^{2}}{L_{s}}\right) \cdot \frac{d I_{r d}}{d t}-g \cdot \omega_{s} \cdot\left(L_{r}-\frac{M^{2}}{L_{s}}\right) \cdot I_{q r} \\
& V_{r q}=R_{r} \cdot I_{r q}+\left(L_{r}-\frac{M^{2}}{L_{s}}\right) \cdot \frac{d I_{r q}}{d t}-g \cdot \omega_{s} \cdot\left(L_{r}-\frac{M^{2}}{L_{s}}\right) \cdot I_{d r}+g \cdot \frac{M \cdot V_{s}}{L_{s}}
\end{aligned}
$$

It exists two methods of Field Orientation Control: [16]

\subsection{Direct Field Orientation Control (DFOC)}

This method consists on regulating the active and reactive stator powers of DFIG independently, by using a PI controller on each axis, while neglecting the coupling terms between the two axes. This method is called direct because the PI controller act directly on the voltages[15][16]; The figure bellow shows the model of direct field orientation control;
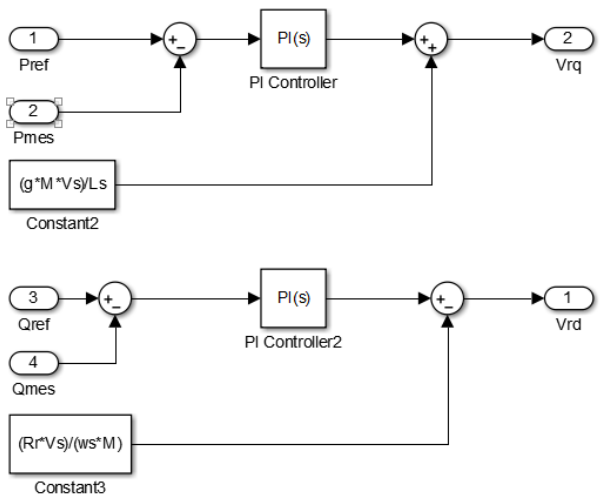

Figure 2. Direct field orientation control

\subsection{Indirect Field Orientation Control(IFOC)}

Unlike direct control and in order to regulate the powers as well as the currents rotor. This method takes into consideration the coupling terms and puts two PI controllers on each axis [2]. The figure bellow shows the model of indirect field orientation control;

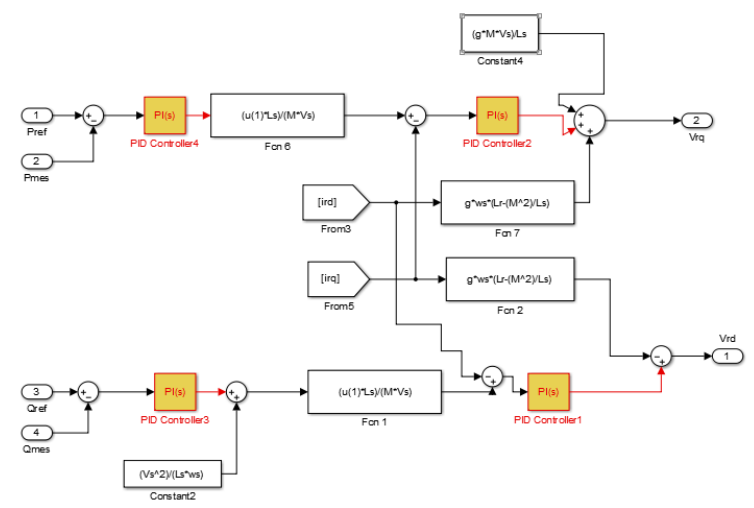

Figure 3. Indirect field orientation control 


\section{RESULT AND ANALYSIS}

The simulation was performed in the Matlab/Simulink environment;

In order to model the wind, we use harmonic sums corresponding to the pulse $\omega$. It is modeled by the following equation:

$$
V=V_{0}+\sum_{i=1}^{n} A_{i} \cdot \sin \left(\omega_{i} t+\Phi_{i}\right)
$$

After applying a random wind profile as shown in 4, from the as shown in 5 and as shown in 6 , it is clear that the system with MPPT control has the coefficient of power $\mathrm{Cp}$ maintained at its maximum value $\mathrm{Cp}=0.5$ and the Paer correctly follows the wind speed,unlike the system without MPPT control. As well as as shown in 7 illustrates the ratio $\lambda$ which is equal to its optimal value.

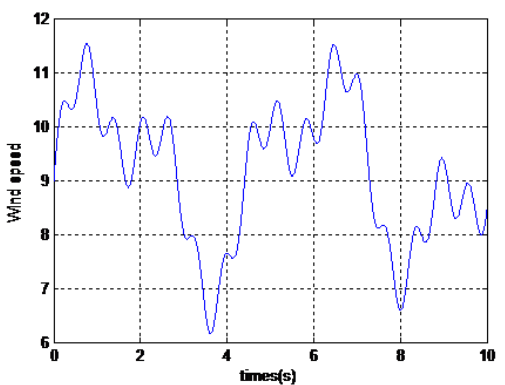

Figure 4. Wind speed

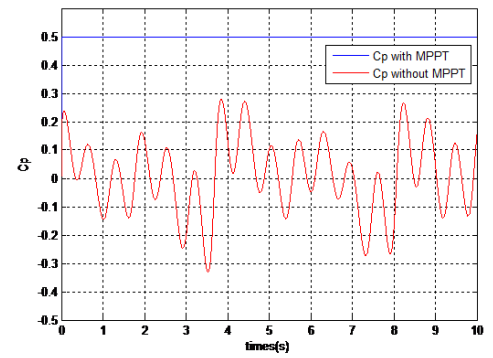

Figure 6. Cp coefficient

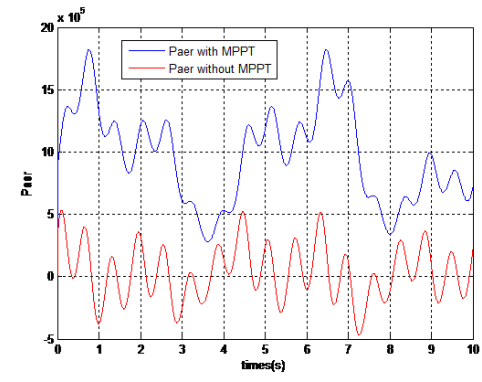

Figure 5. Aerodynamic power

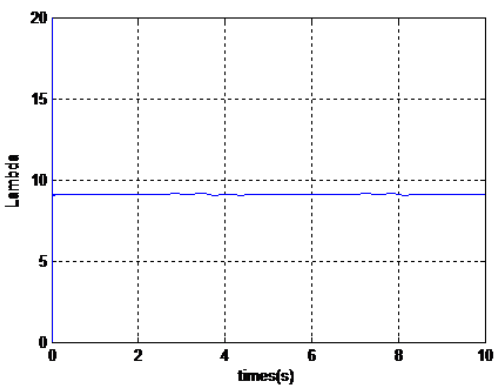

Figure 7. The ratio $\lambda$

To visualize the behavior of the system controls and to be able to compare between the two commads we applied an active and reactive power steps. The active and reactive power steps, which are applied to each type of control, are shown in Table 1.

Table 1. Active and Reactive Power Steps

\begin{tabular}{lccr}
\hline Times(s) & Ps(MW) & times(s) & Qs(MVar) \\
\hline 0 to 0,4 & -0.6 & 0 to 0,2 & -0.6 \\
0,4 to 1,5 & -1 & 0,2 to 1,5 & -1 \\
1,5 to 2,5 & -1.2 & 1,5 to 10 & -1.2 \\
2,5 to 10 & -4 & & \\
\hline
\end{tabular}

The Figure8 and Figure9 show the active and reactive power with direct control, then Figure10 and Figure11 show rotoric current Ird ant Irq.

The Figure 12 and Figure 13 show the active and reactive power with indirect control, and then Figure 14 and Figure15 show the rotor current Ird and Irq. 


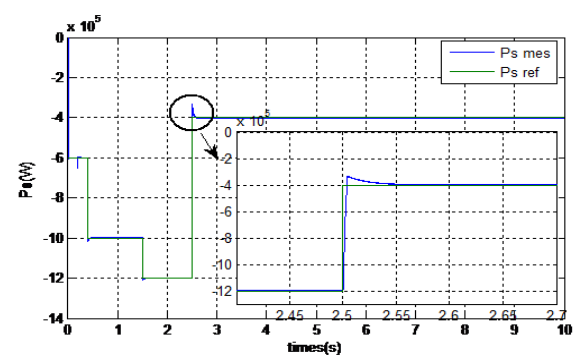

Figure 8. Ps of DFOC

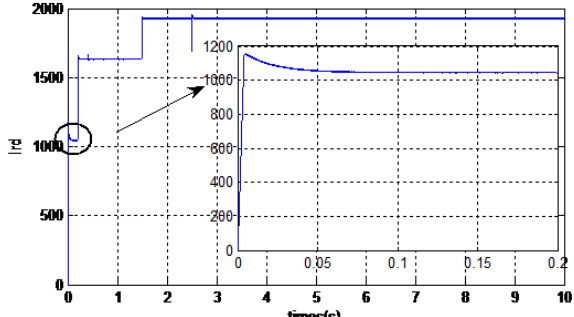

Figure 10. Ird of DFOC

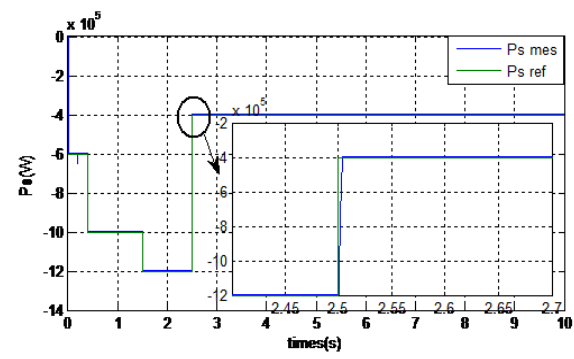

Figure 12. Ps of IFOC

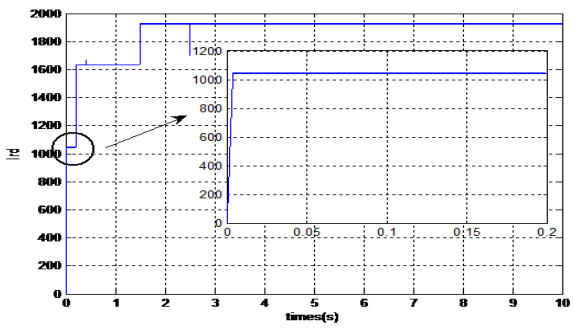

Figure 14. Ird of IFOC

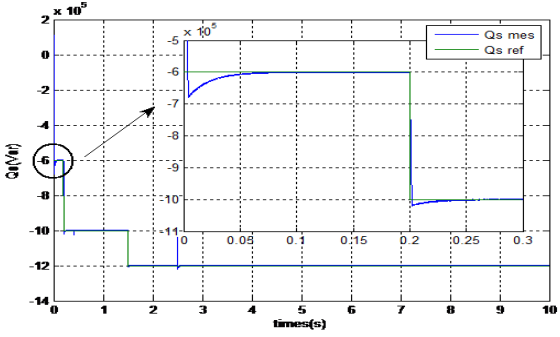

Figure 9. Qs of DFOC

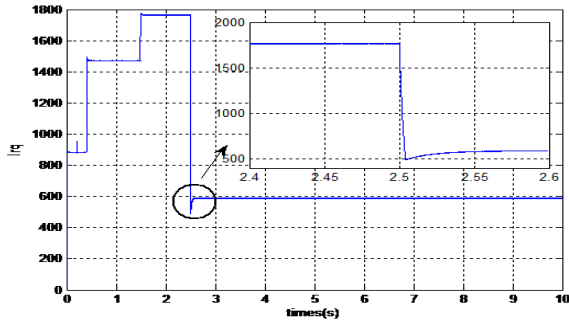

Figure 11. Irq of DFOC

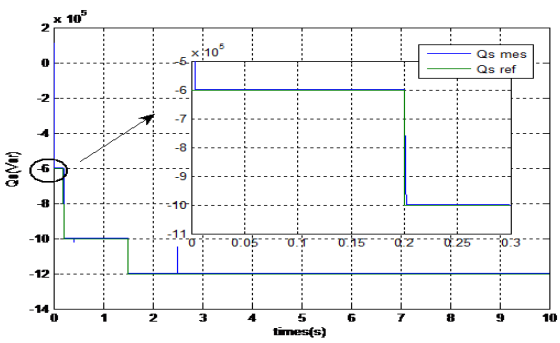

Figure 13. Qs of IFOC

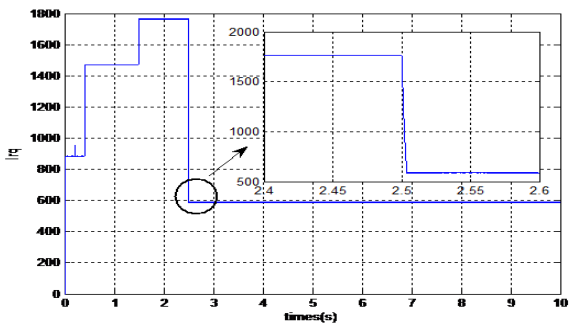

Figure 15. Irq of IFOC

From the previous figures we can see that, active stator power (Ps) depend on the quadrature rotor current (Irq), and also reactive stator power (Qs) depend on the direct rotor current (Ird). So in both cases ( DFOC , IFOC) the decoupling is perfectly ensured.

In the same figures; the system follows the applied instructions except that at the level of the indirect field oriented control we can see very well that, it follows the instruction better than the direct control either for the powers or the currents.

The following table summarizes the comparison of the two types of control in terms of response time $(\mathrm{Tr})$ and Overtaking $(\mathrm{O})$. It is seen that the IFOC control lead to good tracking performance. 
Table 2. Difference between DFOC/IFOC

\begin{tabular}{lcccr}
\hline & $\begin{array}{c}\text { Direct } \\
\mathrm{Rt}(\mathrm{ms})\end{array}$ & $\mathrm{O} \%$ & $\begin{array}{c}\text { Indirect } \\
\mathrm{Rt}(\mathrm{ms})\end{array}$ & $\mathrm{O} \%$ \\
\hline Ps & 50 & 17,5 & 3 & 0 \\
$\mathrm{Qs}$ & 60 & 13,3 & 5 & 0 \\
$\mathrm{Ird}$ & 50 & 9,52 & 4 & 0 \\
$\mathrm{Irq}$ & 60 & 16,66 & 4 & 0 \\
\hline
\end{tabular}

\section{CONCLUSION}

this article deals with the improvement of the power generated from a wind power system. After modeling the whole system ( wind turbine and DFIG generator), fisrt of all, we started with MPPT control to ensure maximum power extraction by fixing $\mathrm{Cp}$ at its maximum value. After that, we are interested in vector control which consists in making the machine similar to a DC machine. Finally, we have have compared the two types of control DFOC and IFOC . In order to validate our study, we have carried out the simulation in the Matlab/Simulink environment .

Based on the simulation results, the MPPT control allows us to exploit the maximum of wind energy to produce the maximum of electrical energy. Also, the vector control is applied carefully . Moreover, we constated that, direct control which is based only on power regulation, is the easiest to implement but not the most efficient. On the other hand, the indirect control where the currents are also controlled is a little complex to implement, but, it ensures a good tracking of the instruction and allows us to have an optimal performance of the system.

\section{REFERENCES}

[1] T. Ackermann and Soder, L. " An Overview of Wind Energy-Status 2002 ", Renewable and Sustainable Energy Reviews, 6(1-2), 67-127 (2002).

[2] S.Mensou, A.Essadki, T.Nasser, B.B.Idrissi, "An Efficient Nonlinear Backstepping Controller Approch of a wind Power Generation System based on a DFIG", International Journal of Renewable Energy Research, Vol.7, No 4, pp.1520-1528, December 2017.

[3] H.Alami, E.Ziani, B.Bossoufi, "Speed control of the doubly fed induction generator applied to a wind system" Journal of Theoretical and Applied Information Technology, pp426-433, Vol.83 No.3, January 2016.

[4] A. Boualouch, A. Essadki, T. Nasser, A. Boukhriss, A. Frigui, "Power Control of DFIG in WECS Using Backstipping and Sliding Mode Controller", International Journal of Electrical Computer Energetic Electronic and Communication Engineering, vol. 9, pp. 612-618, 2015.

[5] B.Bossoufi, S.Ionita, H.Alami Arroussi, M.El Ghamrasni, Y.Ihedrane "Managing voltage drops a variable speed wind turbine connected to the grid", IJAAC International Journal of Automation and Control , Vol.11, No. 1, January 2017.

[6] B.Bossoufi, M.Karim, A.Lagrioui, M.Taoussi, A.Derouich "Observer Backstepping control of DFIGGenerators for Wind Turbines Variable-Speed: FPGA-Based Implementation”, Renewable Energy Journal (ELSIVER), pp 903-917, Vol. 81, September 2015.

[7] M. El Azzaoui, H. Mahmoudi, K. Boudaraia, "Backstepping Control of wind and photovoltaic hybrid Renewable Energy System”.International Journal of Power Electronics and Drive Systems, Vol.7, pp 677686, September 2016

[8] B.Bossoufi, M.Karim, A.Lagrioui, M.Taoussi, M.L.El Hafyani "Backstepping control of DFIG Generators for Wide-Range Variable-Speed Wind Turbines " IJAAC International Journal of Automation and Control , pp 122-140, Vol.8 No.2, July 2014.

[9] S. Mensou, A. Essadki, I. Minka, T. Nasser and B. B. Idrissi, "Backstepping Controller for a Variable Wind Speed Energy Conversion System Based on a DFIG," IEEE International Renewable and Sustainable Energy Conference (IRSEC), pp. 1-6, December 2017.

[10] B.Bossoufi, M.Karim, A.Lagrioui, M.Taoussi "FPGA-Based Implementation nonlinear Backstepping control of a PMSM Drive" IJPEDS International Journal of Power Electronics and Drive System, pp 12-23 Vol.4 No.1, March 2014. 
[11] G. Poddar and V. T. Ranganathan, "Sensorless Double-Inverter-Fed Wound-Rotor Induction-Machine Drive," IEEE Trans. Ind. Electron., Vol. 53, No.1, pp. 86-95, February 2006.

[12] N. El Ouanjli, A. Derouich, A. El Ghzizal, A. Chebabhi, M. Taoussi, "A comparative study between FOC and DTC controls of the Doubly Fed Induction Motor (DFIM) ", IEEE International Conference on Electrical and Information Technologies, Rabat- Morocco 2017.

[13] N. El Ouanjli, M. Taoussi, A. Derouich, A. Chebabhi, A. El Ghzizal, B. Boussoufi "High Performance Direct Torque Control of Doubly Fed Induction Motor using Fuzzy Logic", Gazi university journal of science 31(2),2018.

[14] M. Taoussi, M. Karim, D. Hammoumi, C. Elbakkali, B. Bossoufi, N. El Ouanjli,"Comparative study between Backstepping adaptive and Field-oriented control of the DFIG applied to wind turbines", 3rd IEEE International Conference on Advanced Technologies for Signal and Image Processing, May 2017.

[15] M. Nadour, A. Essadki, T. Nasser. "Comparative Analysis between PI \& Backstepping Control Strategies of DFIG Driven by Wind Turbine”, International Journal of Renewable Energy Research Vol. 7, No 3, pp. 1307-1.

[16] Y. Ihedrane, C. El Bekkali , B. Bossoufi, "Power Control of DFIGGenerators for Wind Turbines Variable Speed”, International Journal of Power Electronics and Drive Systems, Vol. 8, pp. 444-453. March 2017.

\section{BIOGRAPHIES OF AUTHORS}

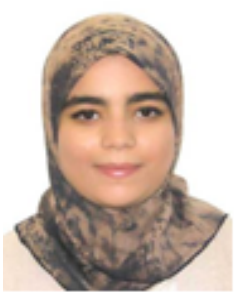

Manale Bouderbala is a Ph.D. Student in Electrical Engineering from Higher school of technology, Oujda Morocco. She is member of laboratory electrical engineering and maintenance (LGEM). She had her master's degree in Engineering of Industrial Automated Systems at the Faculty of Sciences Dhar el Mahrez Fez.

Her research interests include Renewable Energy, static converters, electrical motor drives, and power electronics

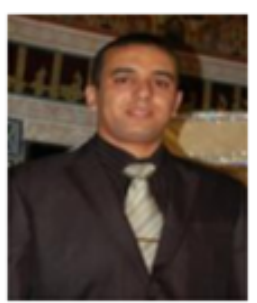

Badre Bossoufi is a Professor of Electrical Engineering, at the Higher School of technology, Oujda Morocco. He is member of laboratory electrical engineering and maintenance(LGEM). He received the Ph.D. degree in Electrical Engineering from University Sidi Mohammed Ben Abdellah, Faculty of Sciences, Morocco and PhD degree from University of Pitesti, Faculty of Electronics and Computer, Romanie and Montefiore Institute of electrical engineering, Luik, Belgium.

his research interests include static converters, electrical motor drives, power electronics, Smart Grid, Renewable Energy and Artificial Intelligent.

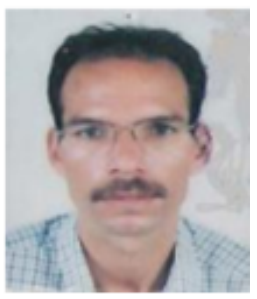

Ahmed Lagrioui is a professor in ENSAM-Mekness, University Mly Smail, Morocco. He received the Ph.D. degree in Electrical Engineering from the Mohammadia school's of engineers, Rabat, Morocco. He received the aggregation degree in electrical engineering from the ENSET School, in 2003. He received the DESA degree in industrial electronics from the Mohammadia school's of engineers.

His research interests include static converters, electrical motor drives and power electronics

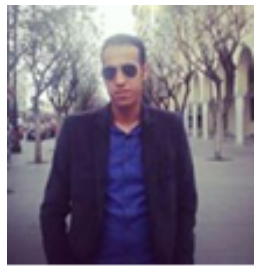

Mohammed Taoussi is a Ph.D. Student in Electrical Engineering from University Sidi Mohammed Ben Abdellah, Faculty of Sciences, Morocco. He received the MASTER degree in industrial electronics from the Faculty of Sciences Fez, in 2013. His research interests include static converters, electrical motor drives, and power electronics, Smart Grid, Renewable Energy and Artificial Intelligence. 


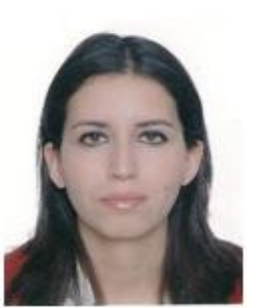

Hala Alami Aroussi received her M.S degree in Industrial Automated Systems Engineering from Sidi Mohammed Ben Abdellah University, Fez, Morocco. She is currently pursuing her $\mathrm{Ph} . \mathrm{D}$ in Electrical Engineering at Mohamed first University, Oujda, Morocco. She is a member of laboratory of electrical engineering and maintenance (LGEM). Her research interests include modeling, control of wind energy conversion systems using a doubly fed induction machine and renewable energy.

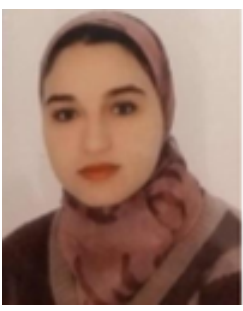

Yasmine Ihedrane obtained her master's degree in Engineering of Industrial Automated Systems at the Faculty of Sciences Dhar el Mahrez -FES- where she currently works, PhD. graduate student in the same university and she is a member of laboratory (LISTA). Her interests in machine control. 